out of the four out-patient teams only one is led by a non psychiatrist despite the added incentive of extra remuneration.

I would therefore conclude that it is not that doctors would like to take charge but that if we don't who will?

JOHN MATHAI, Royal Children's Hospital, Melbourne, Victoria 3052, Australia

Sir: I read with interest the article by Cottrell (Psychiatric Bulletin, 1993, 17, 733-735) on multidisciplinary teams in child and adolescent psychiatry. Child psychiatry is in a peculiar situation as team members take similar patients without much inter-disciplinary differentiation in their work-load. Whether a team member is a medically qualified practitioner, nurse, psychologist, or social worker, children who are depressed, miserable, anxious, phobic, enuretic, or have a conduct disorder or some other diagnosis are taken, and managed. Moreover, most teams seem to have developed an aversion to pharmacological treatment, and therefore do not see the need for the consultant to be kept aware of al patients under his or her care.

If all members of a multidisciplinary team can screen and carry out therapeutic work of a diverse nature, it is likely that soon the realisation will dawn on general managers that the expensive consultant psychiatrists who provide no special input can be dispensed from the multidisciplinary team and concentrated at the tertiary care level to handle the minute percentage of cases that the multidisciplinary team cannot (Arya, 1993).

The justification of consultant psychiatrist as team leader is now 'required' and is an issue of discussion in a multidisciplinary team. It may have nothing to do with the leadership qualities, medical responsibilities, salary or managerial expertise of the consultant but rather that, in child psychiatry now, other team members provide equivalent expertise. No doubt many psychiatrists are beginning to see "the possible benefits of preparing themselves for diffusing authority in order to facilitate a model of care which best meets the needs of our patients" (Cottrell, 1993). Surely, in a multidisciplinary team, a democratic leader can only have claim over leadership if he or she has the advantage of specific expertise.

ARYA, D.K. (1993) Child psychiatric services: in crisis? British Journal of Hospital Medictne, 49, 699.

DINESH K. ARYA, Peter Hodgkinson Centre, County Hospital, Lincoln LN2 $59 Y$

Sir: I suspect that the differences between Dr Mathai and I concerning the functioning of multidisciplinary teams are not great but nevertheless significant. Where we both agree is that teams must have leaders to function efficiently. I also agree that this leader will often be the doctor. However, I do not believe that the doctor should have this role as of right in out-patient teams. I note with interest that Dr Mathai is team leader in his own team, but only after having to apply for the post. I believe that doctors often make excellent team leaders, but that they are better able to fulfil this function, and in particular gain the support of the team, when that team has had a say in the leadership role, rather than when they feel that a leader has been imposed on them.

It follows from this that I would disagree with Dr Mathai's suggestion that the consultant decides to whom referrals should be delegated, after team discussion. I would argue that the team should make this decision after discussion which would, of course, allow the doctor an opportunity for his or her say.

Dr Arya is concerned that consultants may be withdrawn from multidisciplinary teams and held in reserve for dealing with that "minute percentage of cases that the multidisciplinary team cannot handle". This is to misunderstand the model of teamwork that I am proposing. The strength of the multidisciplinary team lies in the team's ability to bring the expertise of all team members to bear on any one referral and to support whichever team member is seeing that case. While it is important to recognise those areas of commonality in the skills of team members, it is equally important to recognise, and respect, those areas of difference which exist. The contribution of a medically trained psychiatrist is, like the contributions of other team members, essential to the effective functioning of the team. Without it the "minute percentage" of cases that the team could not handle would inevitably grow, as it would if any of the core disciplines were absent.

DAVID COTTRELl, Academic Unit of Child and Adolescent Mental Health, 12A Clarendon Road, Leeds LS8 9NN

\section{Diagnosis of personality disorder}

Sir: Like Dr Steadman (Psychiatric Bulletin, 1993, 17, 774), I have found the diagnosis of personality disorder to be used less frequently in recent years; however, I am not sorry to see its decline. In my experience the term is often inappropriate and rarely qualified by subtype or justified by evidence. It thus becomes a diagnostic label which rather than enabling appropriate treatment, actively discourages therapeutic intervention. 